Cite this: Nanoscale, 2014, 6, 9257

\title{
Multispectral upconversion luminescence intensity ratios for ascertaining the tissue imaging depth $\uparrow$
}

\begin{abstract}
Kai Liu, abc Yu Wang, ${ }^{\text {ab }}$ Xianggui Kong, ${ }^{\text {a }}$ Xiaomin Liu, ${ }^{a}$ Youlin Zhang, ${ }^{a}$ Langping Tu, ${ }^{a}$ Yadan Ding, ${ }^{\text {bc }}$ Maurice C. G. Aalders, ${ }^{\star c}$ Wybren Jan Buma ${ }^{\mathrm{b}}$ and Hong Zhang ${ }^{\star b}$

Upconversion nanoparticles (UCNPs) have in recent years emerged as excellent contrast agents for in vivo luminescence imaging of deep tissues. But information abstracted from these images is in most cases restricted to 2-dimensions, without the depth information. In this work, a simple method has been developed to accurately ascertain the tissue imaging depth based on the relative luminescence intensity ratio of multispectral $\mathrm{NaYF}_{4}: \mathrm{Yb}^{3+}, \mathrm{Er}^{3+}$ UCNPs. A theoretical mode was set up, where the parameters in the quantitative relation between the relative intensities of the upconversion luminescence spectra and the depth of the UCNPs were determined using tissue mimicking liquid phantoms. The $540 \mathrm{~nm}$ and $650 \mathrm{~nm}$ luminescence intensity ratios (G/R ratio) of $\mathrm{NaYF}_{4}: \mathrm{Yb}^{3+}, \mathrm{Er}^{3+} \mathrm{UCNPs}$ were monitored following excitation path (Ex mode) and emission path (Em mode) schemes, respectively. The model was validated by embedding $\mathrm{NaYF}_{4}: \mathrm{Yb}^{3+}, \mathrm{Er}^{3+}$ UCNPs in layered pork muscles, which demonstrated a very high accuracy of measurement in the thickness up to centimeter. This approach shall promote significantly the power of nanotechnology in medical optical imaging by expanding the imaging information from 2-dimensional to real 3-dimensional.
\end{abstract}

Received 17th April 2014 Accepted 3rd June 2014

DOI: $10.1039 / c 4 n r 02090 a$

www.rsc.org/nanoscale systematically studied their microscopic luminescence imaging depths by embedding the nanoparticle labeled cells in different animal tissues. ${ }^{18}$ Moreover, benefiting from the abundantly discrete energy level structures of the doped $\mathrm{Ln}^{3+}$ ions, UCNPs show a unique optical property of multiband upconversion luminescence (UCL) spanning from ultraviolet to near infrared, and the spectrum can be modulated by simply varying the doping ions, e.g. Er, Tm, Ho, etc. and/or relevant concentrations. ${ }^{20-24}$ Based on this, multicolor imaging methods can be aptly achieved for simultaneously imaging several different lesions with single $980 \mathrm{~nm}$ excitation. ${ }^{25,26}$ We also developed a multifunctional nanoplatform for cancer cell imaging and photodynamic therapy upon the selective energy transfer from multicolored $\mathrm{NaYF}_{4}: \mathrm{Yb}, \mathrm{Er}$ UCNPs to surface covalently functionalized photosensitizers Rose Bengal (RB). ${ }^{27}$ All these efforts indicated the prospect of UCNPs in tissue imaging and/or therapy.

Despite this progress, how to relate these images to the exact position of the lesion, i.e. how to accurately locate the tissue depth of luminescence probe labeled cancer, remains a big challenge..$^{28,29}$ In clinical oncology it has been proved that the invasion depth has a close relationship with cancer metastasis, ${ }^{30-32}$ and thus the determination of cancer depth is of great significance in cancer staging and prognosis. However, because of the intrinsic complex of the interactions between light and animal tissues (absorption, scattering, reflection, etc.), it is usually difficult to resolve the lesion from traditional singlecolor planar imaging (only lateral distribution of the luminescent probes is acquired) in which the detected signal intensity

${ }^{a}$ State Key Laboratory of Luminescence and Applications, Changchun Institute of Optics, Fine Mechanics and Physics, Chinese Academy of Sciences, Changchun ${ }^{b}$ Van't Hoff Institute for Molecular Sciences, University of Amsterdam, Science Park 904, 1098 XH Amsterdam, The Netherlands. E-mail: h.zhang@uva.nl; Tel: +31-020

ent of Biomedical Engineering and Physics, Academic Medical University of Amsterdam, 1105 AZ Amsterdam, The Netherlands. E-mail: m.c. aalders@amc.uva.nl; Tel: +31-020-566 3829

$\uparrow$ Electronic supplementary information (ESI) available: Absorption spectra of
} 
(A)

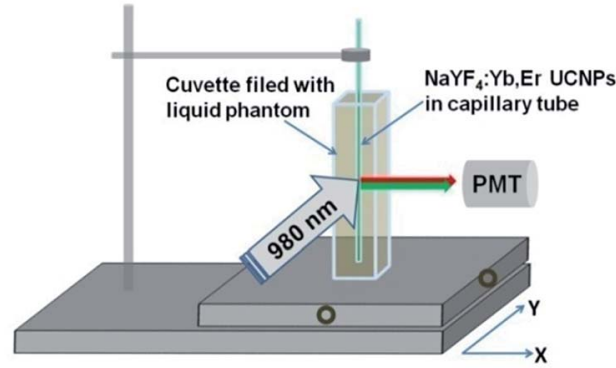

(B) Excitation Mode

(C) Emission Mode

(D) Reflection Mode
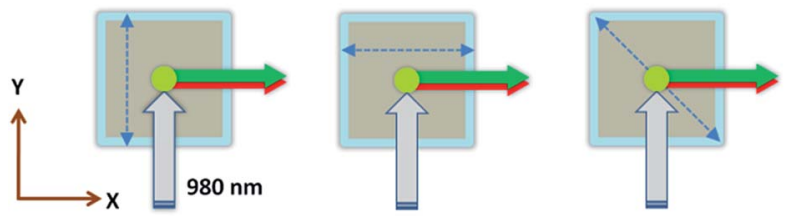

Fig. 1 (A) Schematic of the setup used for light penetration depth dependent UCL spectrum study. (B), (C), and (D) are the three different working modes. The liquid phantom cuvette moves along the directions shown by the dashed lines.

has a nonlinear dependence on the propagation depth in surrounding tissue, especially when the concentration of luminescent probes is taken into account. In this aspect, fluorescence molecular tomography (FMT) has recently been developed to reconstruct fluorescence images. ${ }^{33,34}$ However, this effort is often interfered by the complex light source arrays and detection techniques, and the requirements of intensive computation and complicated data analysis. Moreover, most present FMT techniques have to combine with CT or MRI to improve the photon reconstruction and image visualization. ${ }^{35,36}$ Thus a simple and independent method of evaluating the lesion depth is very demanding.

In this work, we have established a theoretical model which can be used to have an easy but accurate assessment of the depth of luminescence probes embedded in tissue based on multispectral luminescence of UCNPs. The parameters in the deduced quantitative relation between the light propagation depth and the UCL spectrum were fixed from tissue mimicking liquid phantoms, and the setup is depicted in Fig. 1, where UCNPs were encapsulated into a capillary tube and embedded in the tissue mimicking liquid phantoms. The optical pathlength on excitation and emission could be well separately adjusted and the corresponding UCL spectra were recorded by PMT respectively. The integrated intensity ratio of the green and red emission was used for sensing the depth. The deduced relation between the relative intensities and depth was successfully used to determine, with high accuracy, the depth of the UCNPs embedded in pork muscle tissue up to centimeter.

\section{Experiments and methods}

\subsection{Synthesis of $\mathrm{NaYF}_{4}: \mathrm{Yb}, \mathrm{Er}$ UCNPs}

Hydrophobic $\mathrm{NaYF}_{4}: \mathrm{Yb}(20 \%), \operatorname{Er}(2 \%)$ UCNPs of hexagonal phase were firstly synthesized by a solvothermal method according to the literature. ${ }^{37}$ In a typical synthesis procedure,
$236.54 \mathrm{mg} \mathrm{YCl}_{3} \cdot 6 \mathrm{H}_{2} \mathrm{O}(0.78 \mathrm{mmol}), 77.48 \mathrm{mg} \mathrm{YbCl}_{3} \cdot 6 \mathrm{H}_{2} \mathrm{O}$ $(0.2 \mathrm{mmol})$, and $7.64 \mathrm{mg} \mathrm{ErCl}_{3} \cdot 6 \mathrm{H}_{2} \mathrm{O}(0.02 \mathrm{mmol})$ were dissolved in $3 \mathrm{~mL}$ oleic acid (OA) and $7 \mathrm{~mL}$ 1-octadecene (ODE), and heated up to $156{ }^{\circ} \mathrm{C}$ under an argon atmosphere and maintained at that temperature for $1 \mathrm{~h}$ to obtain the OA stable lanthanide precursors. The precursor solution was cooled down to room temperature, then $148.21 \mathrm{mg} \mathrm{NH} \mathrm{NH}_{4} \mathrm{~F}(4 \mathrm{mmol})$ and $100.02 \mathrm{mg} \mathrm{NaOH}(2.5 \mathrm{mmol})$ were added into the solution and heated up to $300{ }^{\circ} \mathrm{C}$ and maintained for $90 \mathrm{~min}$. The received nanoparticles were washed with ethanol at least three times and re-dispersed in $10 \mathrm{~mL}$ hexane.

In order to make the $\mathrm{NaYF}_{4}: \mathrm{Yb}$,Er water dispersible, the hydrophobic ligands of oleic acid (OA) capping outside UCNPs were removed according to a previously reported ligand-free method..$^{38}$ Briefly, $5 \mathrm{~mL}$ of OA capped UCNPs was mixed with 10 $\mathrm{mL} \mathrm{HCl} \mathrm{solution}(\mathrm{pH} \sim 3)$ and then rigorously stirred for $2 \mathrm{~h}$ at room temperature. After that, UCNPs were transferred into the water layer after standing $10 \mathrm{~min}$. The ligand free UCNPs in the water layer were washed with ether 3 times at least and redispersed in $5 \mathrm{~mL}$ water.

\subsection{Liquid phantom experimental stage}

To simulate the UCL attenuation in tissue, a special sample chamber equipped with a two-dimensional (2-D) translation stage was setup in our study, as shown in Fig. 1A. The propagation distance of the excitation light and emission light can be separately controlled. UCNPs, encapsulated in a small glass capillary ( $1 \mathrm{~mm}$ outer diameter) at a concentration of $10 \mathrm{mg} \mathrm{mL}^{-1}$, were dipped into the liquid phantom vertically. The tissue-equivalent liquid phantom ${ }^{39}$ was used as a simulation model and poured into a $10 \mathrm{~mm} \times 10 \mathrm{~mm}$ silica cuvette, which was fixed on the 2-D translation platform. The optical properties were adjusted by the relative concentration of India Ink (absorption component) and Intralipid (scattering component). The spectra at different depths were recorded by PMT in the SPEX system with a $980 \mathrm{~nm}$ laser excitation of $700 \mathrm{~mW} \mathrm{~cm}^{-2}$. In excitation mode (Ex mode, Fig. 1B), the liquid phantom cuvette moves along the excitation direction, i.e. $Y$-axis, in steps of $1 \mathrm{~mm}$, the UCL spectra were recorded at each step with an SPEX spectrophotometer. In emission mode (Em mode, Fig. 1C), the cuvette moves along the emission direction, i.e. $X$-axis, in steps of $1 \mathrm{~mm}$. In reflection mode (Ref mode, Fig. 1D), the cuvette moves along the excitation direction and the emission direction simultaneously.

Considering the absorption difference of real animal tissue at the two wavelengths (540 and $650 \mathrm{~nm}$ ), a second absorption component (Rose Bengal) was also added into the liquid phantoms at different concentrations to simulate further the imaging depth of $\mathrm{NaYF}_{4}: \mathrm{Yb}$,Er nanoparticles in real tissue. The optical properties of liquid phantoms can be well tuned by the relative concentration of the three components India Ink, Rose Bengal and Intralipid. The absorption coefficients and scattering coefficients are given below, sample A: $\mu_{\mathrm{a}}=0.872 \mathrm{~cm}^{-1}, \mu_{\mathrm{s}}^{\prime}=8.2$ $\mathrm{cm}^{-1}(540 \mathrm{~nm}), \mu_{\mathrm{a}}=0.306 \mathrm{~cm}^{-1}, \mu_{\mathrm{s}}^{\prime}=5.2 \mathrm{~cm}^{-1}(650 \mathrm{~nm}) ;$ sample B: $\mu_{\mathrm{a}}=1.362 \mathrm{~cm}^{-1}, \mu_{\mathrm{s}}^{\prime}=8.2 \mathrm{~cm}^{-1}(540 \mathrm{~nm}), \mu_{\mathrm{a}}=0.308 \mathrm{~cm}^{-1}, \mu_{\mathrm{s}}^{\prime}$ $=5.2 \mathrm{~cm}^{-1}(650 \mathrm{~nm})$; sample C: $\mu_{\mathrm{a}}=1.362 \mathrm{~cm}^{-1}, \mu_{\mathrm{s}}^{\prime}=16.4 \mathrm{~cm}^{-1}$ (540 nm), $\mu_{\mathrm{a}}=0.308 \mathrm{~cm}^{-1}, \mu_{\mathrm{s}}^{\prime}=10.4 \mathrm{~cm}^{-1}(650 \mathrm{~nm})$. 


\subsection{Characterization}

Structural characterization was performed with a Philips Morgagni $^{\mathrm{TM}}$ transmission electron microscope (FEI Company, US). UV-Vis absorption spectra of solutions in a quartz cuvette $(1 \mathrm{~cm})$ were recorded with a Hewlett-Packard/Agilent 8453 diode-array biochemical analysis UV-Vis spectrophotometer. The steady-state UCL spectra of UCNPs were detected using a SPEX Fluorolog-3spectrofluorometer (HORIBA JobinYvon, France) where a CW semiconductor diode laser of $980 \mathrm{~nm}$ was used for excitation.

\subsection{Animal tissue depth evaluation using UCNPs}

To validate the methodology of using multicolor UCL imaging to determine the tissue depth, layered pork muscle tissue (thickness $=0.65 \mathrm{~mm}$ ) was utilized as the model. In the experiment, $50 \mu \mathrm{L}$ of $\mathrm{NaYF}_{4}$ :Yb,Er UCNP solution $\left(10 \mathrm{mg} \mathrm{mL}^{-1}\right)$ were firstly dropped onto a layer of pork muscle, which can seep into the tissue within a few seconds. Then more layers of fresh pork muscle (label-free) were covered layer by layer onto the one labeled with UCNPs, and the corresponding UCL spectra at different tissue depths were recorded using an SPEX Fluorolog-3 system under $980 \mathrm{~nm}$ excitation $\left(700 \mathrm{~mW} \mathrm{~cm}^{-2}\right.$ ). The luminescence intensities at $540 \mathrm{~nm}$ and $650 \mathrm{~nm}$ were used for quantitative analysis. The real color UCL imaging was recorded using a Canon Power Shot S120 digital camera by putting an $890 \mathrm{~nm}$ short-pass filter (Semrock) in front to eliminate the scattered $980 \mathrm{~nm}$ laser light.

\section{Results and discussion}

\subsection{Characterization of $\mathrm{NaYF}_{4}: \mathrm{Yb}, \mathrm{Er}$ nanoparticles}

Fig. 2A is the transmission electron microscopy (TEM) image of the ligand free $\mathrm{NaYF}_{4}: \mathrm{Yb}, \mathrm{Er}$ nanoparticles and the average diameter is $39 \mathrm{~nm}$. Fig. 2B is the corresponding selected area electron diffraction (SAED) pattern, which confirms that the assynthesized UCNPs are in hexagonal phase which is known to have high upconversion efficiency. ${ }^{35}$

Fig. $3 \mathrm{~A}$ is the energy level structures of $\mathrm{Yb}^{3+}$ and $\mathrm{Er}^{3+}$ codoped UCNPs and there are two main UPL bands around 540 $\mathrm{nm}$ and $650 \mathrm{~nm}$, respectively. Considering that the allowed excitation power density is limited in animal tissues, we began with the excitation power dependence of the UCL spectrum. The upconversion spectra shown in Fig. 3B were taken under

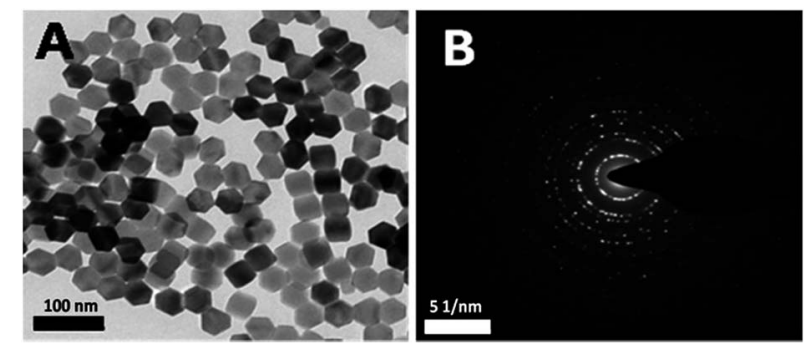

Fig. 2 (A) TEM image of the NaYF 4 :Yb,Er UCNPs. (B) Selected area electron diffraction (SAED) diagram of UCNPS.
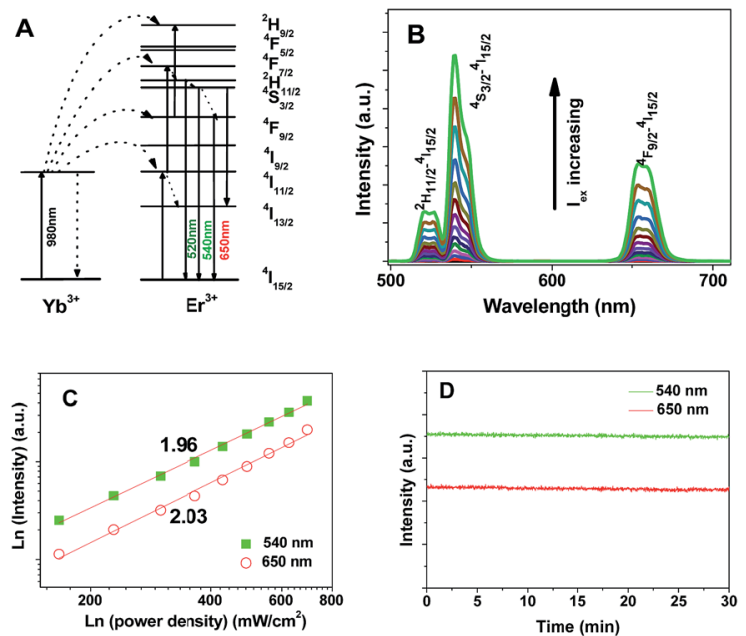

Fig. 3 Optical property results of UCNPs. (A) Upconversion luminescence process in $\mathrm{NaYF}_{4}: \mathrm{Yb}, \mathrm{Er}$ UCNPs. (B) UCL spectra of UCNPs in water $\left(1 \mathrm{mg} \mathrm{mL}^{-1}\right.$ ) under $980 \mathrm{~nm}$ excitation at different excitation power from 175 to $700 \mathrm{~mW} \mathrm{~cm}^{-2}$. (C) Power dependence curves of the two emission bands at $540 \mathrm{~nm}$ and $650 \mathrm{~nm}$. (D) Photostability of the $\mathrm{UCL}$ under $30 \mathrm{~min}$ continuous $980 \mathrm{~nm}$ illumination $\left(600 \mathrm{~mW} \mathrm{~cm}^{-2}\right)$.

relative weak excitation densities from 175 to $700 \mathrm{~mW} \mathrm{~cm} \mathrm{~cm}^{-2}$, well below the UCL saturation threshold. The UCL in the visible region exhibits the feature of $\mathrm{Er}^{3+}$, a green band around $540 \mathrm{~nm}$ and a red one around $650 \mathrm{~nm}$, corresponding to transitions of ${ }^{4} \mathrm{~S}_{3 / 2}-{ }^{4} \mathrm{I}_{15 / 2}$ and ${ }^{4} \mathrm{~F}_{9 / 2}-{ }^{4} \mathrm{I}_{15 / 2}$ in the doped $\mathrm{Er}^{3+}$ ions, respectively (Fig. 3A). The spectra demonstrate a monotonic increase with the excitation power without saturation. The excitation power density dependence of the two UCL bands is shown in Fig. 3C. From the slope of linear fitting in the log-log scale, it can be concluded that the upconversion emission has a quadratic dependence on the $980 \mathrm{~nm}$ excitation power, showing that the UCL originates from two-photon processes, no higher order process is significantly involved. An ideal luminescence marker should have a minimal or no bleaching effect under long time irradiation, thus we studied specifically the photostability of the two UCNP emission bands under 30 min continuous $980 \mathrm{~nm}$ excitation and the results are shown in Fig. 3D. There is no noticeable photodegradation. Based on these studies, we came to the conclusion that UCNPs could serve as ideal contrast agents for long-term luminescence imaging.

\subsection{Depth dependent UCL in liquid phantom}

To study the path-length effects on UCL spectra a 2-D translation platform was built up as shown in Fig. 1A, in which the excitation and emission processes could be separately controlled by simply adjusting the liquid phantom cuvette along different directions. Fig. 4 are the extinction spectra of the different components of the liquid phantom used in our study. India Ink and Intralipid were served respectively as the main absorption and scattering components. From the spectra we can see that their extinction coefficients at short wavelength (e.g. $540 \mathrm{~nm})$ are higher than those at longer wavelength (e.g. $650 \mathrm{~nm})$. Both the Intralipid and India Ink have linear response of extinction 

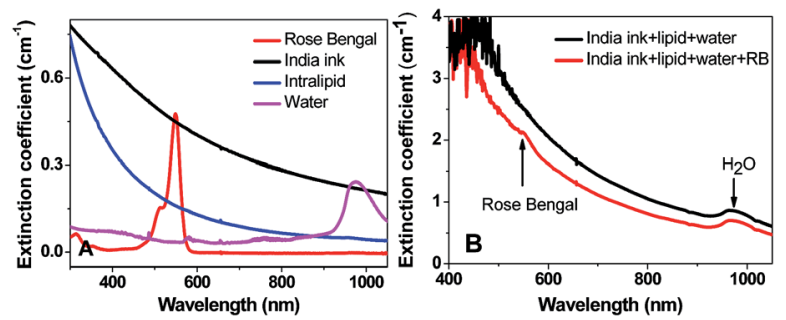

Fig. 4 (A) Wavelength dependent extinction coefficients of the components of the liquid phantom. (B) Extinction spectra of the liquid phantom without (black curve) and with (red curve) Rose Bengal.

coefficients to their concentrations (Fig. S1 and S2 in the ESI $\dagger$ ), thus we could control the optical properties by modulating the relative concentrations of the two. Since the hemoglobin in real animal tissue has high absorption around $540 \mathrm{~nm}$, Rose Bengal was also added into the liquid phantom to further enhance the absorption in this spectral region. Fig. 4B shows the extinction spectra of liquid phantoms with and without Rose Bengal. The small peak detected around $540 \mathrm{~nm}$ in the red curve can be attributed to the characteristic absorption of Rose Bengal. The UCL spectra recorded in Em-, Ex- and Ref modes are shown in Fig. S3A-C in the ESI, $\uparrow$ and the corresponding integrated intensities of the green and the red bands are given in Fig. 5A-C (mono-logarithm scale). In Ex mode (Fig. 5A), both the green and red emissions attenuate exponentially with the same slope ( $\sim-4.3$ ), indicating that the spectral shape does not vary with the propagation path-length of the excitation light. Here the contribution of surface reflection is already excluded. In Em mode (Fig. 5B), however, the green band attenuates faster than the red one, which is understandable because the liquid phantom absorbs and scatters more at shorter wavelength (Fig. 4). The fitted attenuation slopes are -3.25 and -2.72 for the green and red bands, respectively. The slope difference between Ex- and Em modes is related to the two photon nature of the UCL
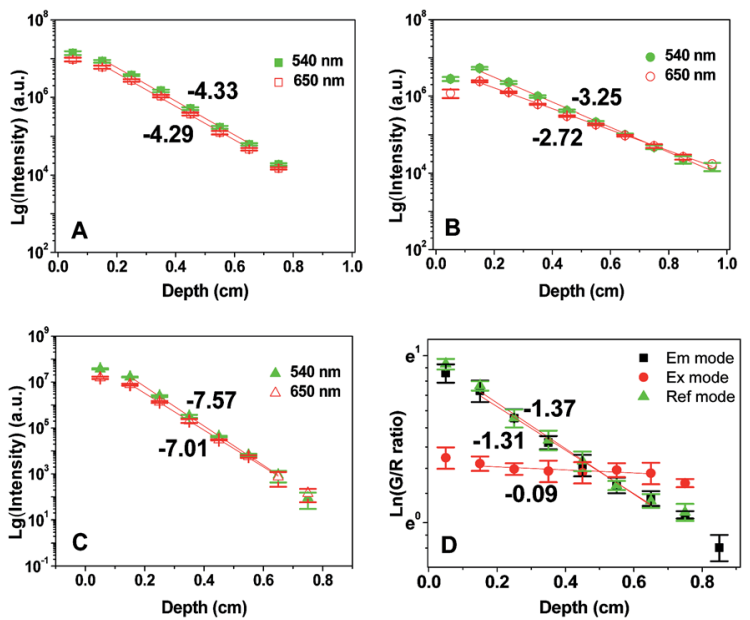

Fig. 5 Penetration depth dependence of the UCL intensities in (A) Ex mode, (B) Em mode, and (C) Ref mode in liquid phantoms $10.025 \%$ India Ink and $0.5 \%$ Intralipid). (D) G/R ratio in the three modes. Error bars are marked in the figures. process. Fig. 5C shows the fitted slopes of Ref mode; both emission bands attenuate significantly with depth; the fitted attenuation slopes are -7.57 and -7.01 , respectively. The attenuation slopes in Ref mode are found to be exactly the sum of the slopes in Ex- and Em modes. In Fig. 5D, we show the penetration depth dependent intensity ratio of green/red UCL (G/R ratio). Exponential relation is found in Em- and Ref modes, whereas it remains almost constant in Ex mode. This indicates that the propagation path-length of excitation light has a negligible effect on the $\mathrm{G} / \mathrm{R}$ ratio.

\subsection{Theoretical model}

In our experiments the $980 \mathrm{~nm}$ laser was collimated into a planar beam of $10 \mathrm{~mm}^{2}$ to excite the UCNP capillary tube embedded in the cuvette that is filled with liquid phantoms. The UCL was thus treated as a line light source, and the energy fluence attenuated isotropically in the tissue. Based on the optical diffusion theory, ${ }^{40,41}$ the distribution of the excitation light and the emission light along their propagation direction $(z)$ inside tissue could be written as:

$$
\begin{array}{r}
D_{\mathrm{x}} \frac{\mathrm{d}^{2} \Phi_{\mathrm{x}}(z)}{\mathrm{d} z^{2}}-\mu_{\mathrm{a}, \mathrm{x}} \Phi_{\mathrm{x}}(z)=-\mu_{\mathrm{s}, \mathrm{X}}^{\prime} P_{\mathrm{x} 0} \mathrm{e}^{-\mu_{\mathrm{t}, \mathrm{x}}^{\prime} z} \\
\frac{\mathrm{d}^{2} \Phi_{\mathrm{m}}(z)}{\mathrm{d} z^{2}}+\frac{2}{z} \frac{\mathrm{d} \Phi_{\mathrm{m}}(z)}{\mathrm{d} z}-\mu_{\mathrm{eff}, \mathrm{m}}^{2} \Phi_{\mathrm{m}}(z)=-\frac{P_{\mathrm{m} 0}}{D_{\mathrm{m}}} \delta(z)
\end{array}
$$

here $\Phi_{\mathrm{x}}$ and $\Phi_{\mathrm{m}}$ and are the influent intensities of excitation light and emission light inside the tissue, $P_{\mathrm{x} 0}$ and $P_{\mathrm{m} 0}$ are the initial intensities of the incident excitation light $($ e.g. $980 \mathrm{~nm})$ and the emission light (e.g. 540 or $650 \mathrm{~nm}$ ), $\mu_{\mathrm{a}, \mathrm{x}}, \mu_{\mathrm{s}, \mathrm{x}}^{\prime}$ and $\mu_{\mathrm{t}, \mathrm{x}}^{\prime}$ are the absorption coefficient, reduced scattering coefficient and the total attenuation coefficient for the excitation light, $\mu_{\text {eff,m }}$ is the effective attenuation coefficient for the emission light, $D_{\mathrm{x}}$ and $D_{\mathrm{m}}$ are the diffusion coefficients of excitation and emission, respectively. The solution for the emission diffusion equations is:

$$
\Phi_{\mathrm{m}}(z)=\frac{P_{\mathrm{m} 0}(z) \mathrm{e}^{-\mu_{\mathrm{ef}, \mathrm{m}} z}}{4 \pi D_{\mathrm{m}} z}
$$

From eqn (3) we can see that the fluorescence energy fluence $\Phi_{\mathrm{m}}$ is affected not only by the initial luminescence intensity $P_{\mathrm{mo}}$ but also by the tissue optical property $\mu_{\text {eff,m }}$. Regarding NaY$\mathrm{F}_{4}: \mathrm{Yb}$,Er UCL, we can divide the fluorescence energy fluence into two parts $\Phi_{540}$ and $\Phi_{650}$, corresponding to the two emission bands around 540 and $650 \mathrm{~nm}$, respectively. The intensity ratio $R$ detected is therefore:

$$
\begin{aligned}
R=\frac{\Phi_{540}(z)}{\Phi_{650}(z)} & =\frac{\frac{P_{0,540}(z) \mathrm{e}^{-\mu_{\text {eff }, 540} z}}{4 \pi D_{540} z}}{\frac{P_{0,650}(z) \mathrm{e}^{-\mu_{\text {eff }, 650} z}}{4 \pi D_{650} z}} \\
& =\frac{P_{0}^{540}(z)}{P_{0}^{650}(z)} \frac{D_{650}}{D_{540}} \mathrm{e}^{-\left(\mu_{\text {eff }, 540}+\mu_{\text {eff }, 650}\right) z}
\end{aligned}
$$




$$
\mu_{\mathrm{eff}}^{2}=3 \mu_{\alpha} \mu_{\mathrm{t}}^{\prime}=3 \mu_{\alpha}\left(\mu_{\alpha}+\mu_{\mathrm{s}}^{\prime}\right)
$$

The first item at the right side of eqn (4) is constant that is determined by the intrinsic optical properties of UCNPs, as proved in Fig. 5A. And the diffusion coefficients $D_{540}$ and $D_{650}$ in the second part are also constant for a homogeneous tissue. Thus from this equation we can deduce that the $G / R$ ratio detected at the surface follows an exponential decay pattern with increasing the tissue depth, and the attenuation slope can be calculated from the difference of effective attenuation coefficients at these two wavelengths.

\subsection{Ascertaining the tissue imaging depth with multispectral upconversion luminescence}

'Real tissue' contains hemoglobin and other chromophores, which lead to more absorption around $540 \mathrm{~nm}$ compared to 650 $\mathrm{nm}$. To mimic this, studies were performed in liquid phantoms with different optical properties by varying the concentration of India Ink, Rose Bengal and Intralipid. The corresponding attenuation slopes detected in Ref mode are given in Fig. 6 (the corresponding spectra data are given in Fig. S4-S6 in the ESI $\dagger$ ). In sample $A$, the attenuation slopes are -5.46 and -4.71 for green and red bands, respectively (Fig. 6A). Adding more RB into the phantom, the slope of the green band changes to -5.95 while the red band remains almost constant ( -4.74 , Fig. 6B). This is because RB has maximal absorption around $540 \mathrm{~nm}$, which makes the green band attenuate faster. In Fig. 6C, more Intralipid is in sample $B$, the scattering increases while the absorption remains the same around $540 \mathrm{~nm}$ and $650 \mathrm{~nm}$. Sharper decreases of the intensities are observed with the slopes of -6.12 and -5.23 , which is predictable since scattering is enhanced in both excitation and emission. Fig. 6D shows the $\mathrm{G} / \mathrm{R}$ ratio of samples $\mathrm{A}, \mathrm{B}$ and $\mathrm{C}$, where the fitted slopes are $-1.72,-2.76$ and -2.80 , respectively. Deviating from sample A,
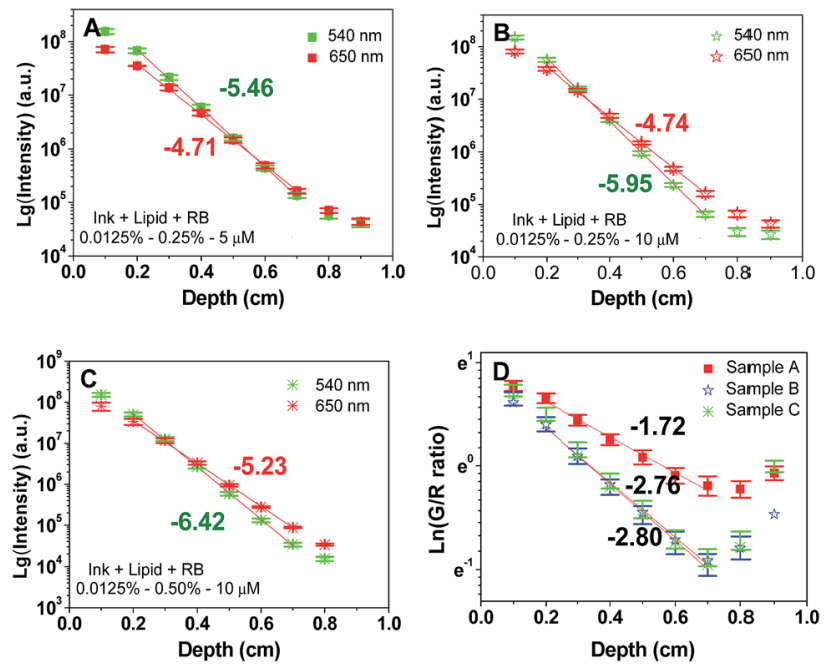

Fig. 6 (A), (B) and (C) are the depth dependent $U C L$ intensities detected in three liquid phantom samples with different components. (D) is the corresponding G/R intensity ratio attenuation curves of the three samples. Error bars are marked in the figures. the slope variations are approximately the same for samples B and $\mathrm{C}$ although they have different amounts of Intralipid (the amount of India Ink/Rose Bengal was the same). This result tells us that the $\mathrm{G} / \mathrm{R}$ intensity ratio is more sensitive to the absorption coefficient than the scattering coefficient. In fact it is in line with eqn (4) and (5), where the effective attenuation coefficient has a linear relationship with $\mu_{\mathrm{s}}$ but a quadratic one with $\mu_{\mathrm{a}}$.

So far we have built up the quantitative relationship between the propagation depth of UCNPs in tissue mimic liquid phantoms and the UCL spectra. In the following, we will validate the method employing layered pork muscle tissue. Fig. S7† shows the extinction spectra of pork muscle with different thicknesses (or layers). As pork muscles contain a high concentration of myohemoglobin which has relatively high absorption around $540 \mathrm{~nm}$, the effective attenuation coefficient is thus higher than that of $650 \mathrm{~nm}$. The photographs in Fig. 7A and B are the real color UCL images recorded in Ex- and Em modes, respectively. The incident excitation power density at $980 \mathrm{~nm}$ was $700 \mathrm{~mW}$ $\mathrm{cm}^{-2}$ at the surface. In Ex mode, although the emission intensity dropped proportionally with the tissue depth (the actual
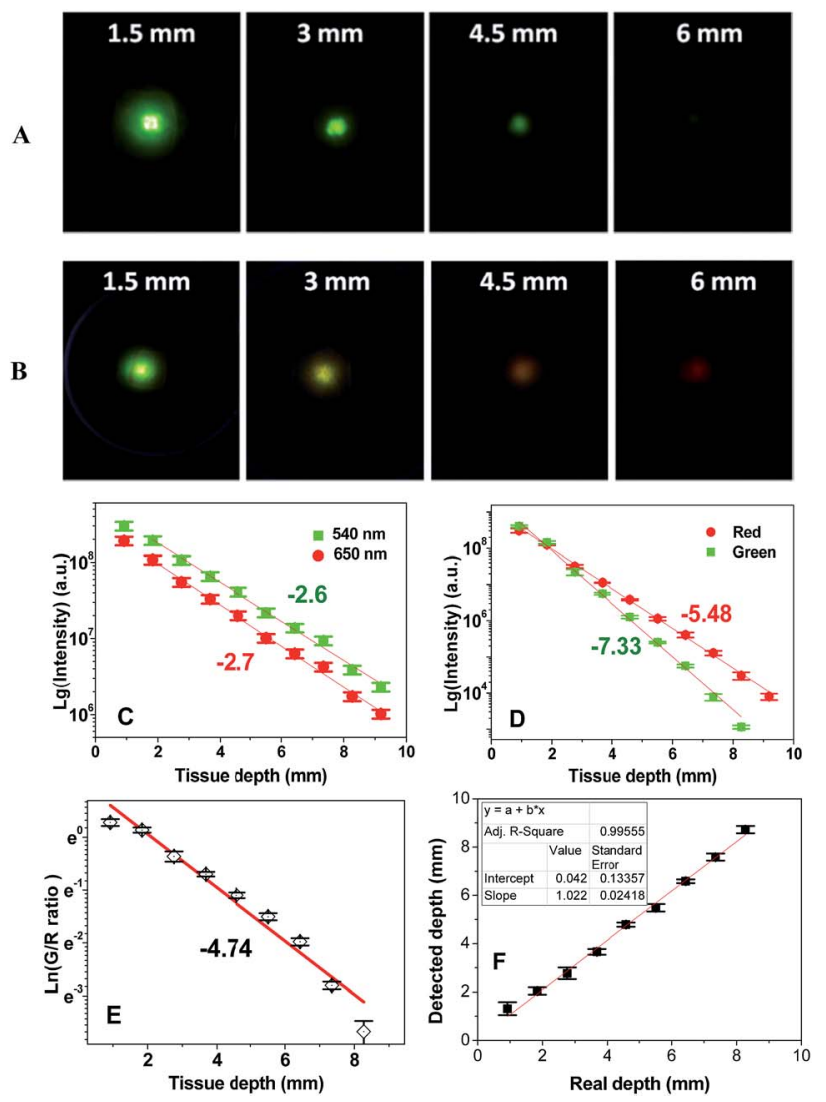

Fig. 7 UCL imaging in layered pork muscle tissue at different depths in Ex mode (A) and Em mode (B); (C) and (D) are the corresponding $U C L$ intensities detected in Ex mode and Ref mode, respectively; $(E)$ is the corresponding $\mathrm{G} / \mathrm{R}$ ratio attenuation curves in Ref mode. (F) The measured depth of pork muscle versus the real depth. Error bars are marked in the figures. The error bars in (F) are due to the distribution of nanoparticles in the bottom pork layer. 
excitation power decreased), the color remained unchanged. In contrast, the color of UCL in Em mode changed from green to red with the tissue depth, reflecting the higher absorption of muscle hemoglobin to $540 \mathrm{~nm}$ emission. More quantitative analyses were carried out by recording the UCL spectra at different depths of Em-, Ex- and Ref modes (data are shown in Fig. S8-S10 in the ESI $\dagger$ ), and the UCL intensities around $540 \mathrm{~nm}$ and $650 \mathrm{~nm}$ are given in Fig. 7C and D. Fig. 7C is the depth dependent UCL intensity recorded in Ex mode, where a similar tissue penetration depth dependence is observed for the green and the red emission. Fig. 7D shows the results of Ref mode; the slopes for green and red bands are -7.33 and -5.48 , respectively. To determine the reproducibility of the results, all the spectra are recorded at least three times for each tissue depth. The results as shown in Fig. 7D are reproducible with the error bar less than $10 \%$. Compared with the results on liquid phantoms, the $\mathrm{G} / \mathrm{R}$ attenuation slope in pork muscle is much higher $(-4.74)$, as shown in Fig. 7E. This discrepancy might attribute to the higher effective coefficient difference of the two bands in the pork muscles than that in the liquid phantoms. As the G/R ratio detected is determined by the inherent properties of NaY$\mathrm{F}_{4}: \mathrm{Yb}$,Er UCNPs, which is independent of the absolute amount of UCNPs and the excitation power density at the low density level. To prove this hypothesis, different amounts of UCNPs were further embedded in the bottom pork layer and the ascertained tissue depth (as shown in Fig. 7F) was calculated from the G/R ratio (data are shown in Fig. S11 $\dagger$ ). From the linear fitting we see that the calculated depths are in excellent agreement with the actual tissue ones. The standard error is less than $0.15 \mathrm{~mm}$ in the range $1-10 \mathrm{~mm}$. In a word, the multispectral UCL imaging can be utilized as an effective method to accurately ascertain the UCNP depth in tissue, i.e. the marked lesion depth position can be accurately determined, which has great potential in tissue engineering and disease diagnosis.

\section{Conclusions}

In conclusion, a theoretical model has been established to relate the relative intensities of the UCL spectra to the tissue imaging depth of UCNPs. The method was validated in liquid phantoms and pork muscle tissue. Although in this work we have focused on $\mathrm{NaYF}_{4}: \mathrm{Er}^{3+}, \mathrm{Yb}^{3+}$ UCNPs, other upconversion materials can be similarly employed as well for even better penetration, e.g. introducing $\mathrm{Tm}^{3+}$. This new approach shall lift significantly the power of nanotechnology assisted luminescence imaging by providing also accurate information of the depth of UCNP labeled lesion.

\section{Acknowledgements}

This work was supported by the NSF of China (61275197, 21304084, 11374297, and 51372096), the Joint research program between KNAW of The Netherlands and CAS of China, the IOP program of the Netherland and John van Geuns Foundation.

\section{Notes and references}

1 V. Ntziachristos, C. Bremer and R. Weissleder, Eur. Radiol., 2003, 13, 195.

2 P. P. Ghoroghchian, M. J. Therien and D. A. Hammer, Wiley Interdiscip. Rev.: Nanomed. Nanobiotechnol., 2009, 1, 156.

3 M. Bates, B. Huang, G. T. Dempsey and X. Zhuang, Science, 2007, 317, 1749.

4 G. Chen, H. Qiu, P. N. Prasad and X. Chen, Chem. Rev., 2014, 114, 5161.

5 T. Yang, Y. Sun, Q. Liu, W. Feng, P. Yang and F. Li, Biomaterials, 2012, 33, 3733.

6 J. Wang, F. Wang, C. Wang, Z. Liu and X. Liu, Angew. Chem., Int. Ed., 2011, 50, 10369.

7 Q. Liu, W. Feng, T. Yang, T. Yi and F. Li, Nat. Protoc., 2013, 8, 2033.

8 C. Vinegoni, D. Razansky, S. A. Hilderbrand, F. Shao, V. Ntziachristos and R. Weissleder, Opt. Lett., 2009, 34, 2566.

9 T. Y. Cao, Y. Yang, Y. A. Gao, J. Zhou, Z. Q. Li and F. Y. Li, Biomaterials, 2011, 32, 2959.

10 A. P. Popov, A. V. Bykov, V. I. Sokolov, Y. V. Lysak, A. Nadort, A. V. Priezzhev, R. Myllylä and A. V. Zvyagin, Proc. SPIE, 2011, $80900 \mathrm{~V}$.

11 C. T. Xu, N. Svensson, J. Axelsson, P. Svenmarker, G. Somesfalean, G. Chen, H. Liang, L. Haichun, Z. Zhiguo and S. Andersson-Engels, Appl. Phys. Lett., 2008, 93, 171103.

12 T. V. Esipova, X. Ye, J. E. Collins, S. Sakadzic, E. T. Mandeville, C. B. Murray and S. A. Vinogradov, Proc. Natl. Acad. Sci. U. S. A., 2012, 109, 20826.

13 G. Chen, J. Shen, T. Y. Ohulchanskyy, N. J. Patel, A. Kutikov, Z. Li, J. Song, R. K. Pandey, H. Agren, P. N. Prasad and G. Han, ACS Nano, 2012, 6, 8280.

14 P. Svenmarker, C. T. Xu and S. Andersson-Engels, Opt. Lett., 2010, 35, 2789.

15 X. Wang, J. T. Chen, H. Zhu, X. Chen and X. P. Yan, Anal. Chem., 2013, 85, 10225.

16 X. Li, Z. Li, W. Gan, T. Wang, S. Zhao, Y. Lu, J. Cheng and G. Huang, Analyst, 2013, 138, 3711.

17 P. Ma, H. Xiao, X. Li, C. Li, Y. Dai, Z. Cheng, X. Jing and J. Lin, Adv. Mater., 2013, 25, 4898.

18 S. Nagarajan and Y. Zhang, Nanotechnology, 2011, 22, 395101.

19 B. Dong, S. Xu, J. Sun, S. Bi, D. Li, X. Bai, Y. Wang, L. Wang and H. Song, J. Mater. Chem., 2011, 21, 6193.

20 J. Wang, H. Song, W. Xu, B. Dong, S. Xu, B. Chen, W. Yu and S. Zhang, Nanoscale, 2013, 5, 3412.

21 F. Wang and X. Liu, J. Am. Chem. Soc., 2008, 130, 5642.

22 Z. Li, Y. Zhang and S. Jiang, Adv. Mater., 2008, 20, 4765.

23 R. Chen, V. D. Ta, F. Xiao, Q. Zhang and H. Sun, Small, 2013, 9, 1052.

24 L. Cheng, K. Yang, M. Shao, S.-T. Lee and Z. Liu, J. Phys. Chem. C, 2011, 115, 2686.

25 Q. Dou, N. M. Idris and Y. Zhang, Biomaterials, 2013, 34, 1722. 
26 L. Cheng, K. Yang, S. Zhang, M. Shao, S. Lee and Z. Liu, Nano Res., 2010, 3, 722.

27 K. Liu, X. Liu, Q. Zeng, Y. Zhang, L. Tu, T. Liu, X. Kong, Y. Wang, F. Cao and S. A. Lambrechts, ACS Nano, 2012, 6, 4054.

28 V. Ntziachristos, J. Ripoll, L. H. V. Wang and R. Weissleder, Nat. Biotechnol., 2005, 23, 313.

29 F. Leblond, S. C. Davis, P. A. Valdes and B. W. Pogue, J. Photochem. Photobiol., B, 2010, 98, 77.

30 J. Jung, N. Cho, J. Kim, E. Choi, S. Lee, H. Byeon, Y. Park, W. Yang and S. H. Kim, Int. J. Oral Surg., 2009, 38, 653.

31 M. Hirose, H. Fukui, Y. Igarashi, Y. Fujimori, Y. Katake, A. Sekikawa, K. Ichikawa, S. Tomita, J. Imura and Y. Ajioka, J. Gastroenterol., 2010, 45, 1212.

32 M. Pentenero, S. Gandolfo and M. Carrozzo, Head Neck, 2005, 27, 1080.

33 X. Montet, V. Ntziachristos, J. Grimm and R. Weissleder, Cancer Res., 2005, 65, 6330.
34 C. T. Xu, P. Svenmarker, H. Liu, X. Wu, M. E. Messing, L. R. Wallenberg and S. Andersson-Engels, ACS Nano, 2012, 6, 4788.

35 M. Nahrendorf, P. Waterman, G. Thurber, K. Groves, M. Rajopadhye, P. Panizzi, B. Marinelli, E. Aikawa, M. J. Pittet and F. K. Swirski, Arterioscler.Thromb.Vasc.Biol., 2009, 29, 1444.

36 C. M. McCann, P. Waterman, J. L. Figueiredo, E. Aikawa, R. Weissleder and J. W. Chen, NeuroImage, 2009, 45, 360.

37 H.-S. Qian and Y. Zhang, Langmuir, 2008, 24, 12123.

38 N. Bogdan, F. Vetrone, G. A. Ozin and J. A. Capobianco, Nano Lett., 2011, 11, 835.

39 S. T. Flock, S. L. Jacques, B. C. Wilson, W. M. Star and M. J. van Gemert, Lasers Surg. Med., 1992, 12, 510.

40 M. A. Mycek and B. W. Pogue, Handbook of Biomedical Fluorescence, CRC Press, 2003.

41 T. J. Farrell, M. S. Patterson and B. Wilson, Med. Phys., 1992, 19, 879 . 